are not discussed. Neither are the very broad, qualitative statements about the definition of minimal risk - a crucial issue - any more precise than 20 years ago.

Saddest of all is the ignoring of the empirical studies of Priscilla Alderson in the UK, which should be revolutionising the involvement of children in medical decision-making. A long chapter on the latter is based largely on psychological constructs, from which comes a rather fuzzy message that only older adolescents are capable of consenting to research involvement.

Yet Dr Alderson has shown that children as young as seven have the ability to give informed consent, not just the assent that is all that the American authors think them capable of. Recognising that ability allows one to work in partnership with children and parents. The problem with Children as research subjects is that it still regards research with children as a paternalistic activity and does not address the possibility of it being a partnership. Yet were that paternalism full-blooded, it would wish to reverse the erosion of children's protection in research. Because the authors do not consider the debates outside the United States, they are caught, untenably, between paternalistic and respectful approaches to protecting children. Recognition of the great amount that children can and do understand about medical proposals demands respect for them, which should translate into the practice of research as a common enterprise, a partnership - an idea first proposed in fact by a great American, Margaret Mead, a quarter of a century ago.

DR RICHARD NICHOLSON Editor, Bulletin of Medical Ethics

\section{The Healing Arts: an Oxford Illustrated Anthology}

Edited by R S Downie, Oxford, Oxford University Press, 334 pages, $£ 18.99$.

This book is a gem which will have wide appeal. The chosen title emphasises that the arts and medicine have the common purpose of healing dis-ease. It breaks new ground in using art, prose and poetry to explore interactions between medicine and the arts. The purpose is to provide multiple perspectives and deep insights into the reactions of patients, their friends, doctors, and others to disabilities, illness and other life events.

The extracts and illustrations are all well chosen and illuminating; taken together they build up a varied and valuable whole that fulfils the ambitious aim of the book, as well as being stimulating and entertaining. The editor's commentary steers us through the chosen topics with a skilful but light touch, leaving the poets, authors and artists to build up the rich canvas. Readers are likely to be stimulated to seek out and read in full much of the source material.

The contributions blend into a structured miscellany, providing new viewpoints on the varied ways that people think, feel, manage, or fail to cope as they experience the events that characterise the human condition. The authors and artists vary from household names to the relatively unknown, and include such diverse sources as Pepys on the great plague, travels with Lord Byron, Zen and the Art of Motorcycle Maintenance, Catch 22, a case study of Beethoven, poems by Philip Larkin, William Blake and John Donne, and portraits by Rembrandt and Sir Roy Calne. The book is divided into sections covering areas such as birth, growing up, love, maturity and ageing, disease and mental illness, doctors and psychiatrists, nurses and patients, healing, caring, death and dying. Many of the extracts chosen will deepen mutual understanding between professionals and patients.

This book can with profit be dipped into anytime, but I hope it will also be read, thought about and valued. There is much in it that we need to learn and understand.

RICHARD WEST Medical Postgraduate Department, University of Bristol

\section{Ethics and Perinatology}

\section{Edited by A Goldsworth, W} Silverman, D K Stevenson, E W D Young and R Rivers, Oxford, Oxford University Press, 1995, 484 pages, $£ 50.00$.

This book of US/UK origin is a major text which covers most of the main moral, legal and economic issues generated by the practice of perinatology in the Western world. The contents are interestingly arranged, with each of the 14 topics being introduced by an experienced clinician and followed by an extensive commentary by an appropriate expert from the fields of academic law, bioethics, health economics or philosophy. This method has succeeded because each of the contributions from the team of 32 well-chosen authors is of high quality and is well-fitted to the intended design.

The avowed purpose is to "address ethical issues confronted by those caring for fetuses, newborns and their families" but the emphasis is almost entirely on those dilemmas closely touching the providers and recipients of treatment in neonatal intensive care units (NICUs).

This field of technologically driven medical and nursing practice is now sufficiently established and demarcated to justify an ethical compendium devoted to the specialty. But the thoughtful question asked on page 327 by Margaret Brazier: "Are there in reality ethical problems of perinatology, or are such problems particular applications of more general issues concerning prolonging life and the euthanasia controversy?" is not fully answered.

The ethical frame is the now conventional US/UK paradigm of medico-moral reasoning: Hippocratic code, the four pillars of philosophic principle enunciated by Beauchamp and Childress, commitment to a pluralistic interpretation of the golden rule and a leaning towards a utilitarian ethic in which fairness replaces felicity.

The sections on: prolonging life and causing death, the participation of infants in research, informed consent, organ transplant and the economics of cost-hungry intensive care show that there are difficulties in generalising the "principled" approach to some particular perinatal situations.

Informative and useful chapters about the body of legal and regulatory measures which impact on perinatal practice reveal interesting differences between US and UK attitudes and processes. The extent to which these account for variation in clinical behaviours and ethical decisionmaking is worthy of further discussion.

Some consideration of the non-rational elements which complement the philosophical analytic approach surfaces in a plea for a more virtue-based ethics from the writers on paediatric nursing, and in the two illuminating chapters on religious influences. One is 